\title{
Development of an easy-to-use urease kit for detecting Helicobacter pylori in canine gastric mucosa
}

\author{
Chularat Hlaoperm ${ }^{1,2}$, Kiattawee Choowongkomon ${ }^{3}$ (D) Chantima Pruksakorn ${ }^{4}\left(\mathbb{D}\right.$ and Jatuporn Rattanasrisomporn ${ }^{1,2} \mathbb{D}$ \\ 1. Graduate Program in Animal Health and Biomedical Sciences, Faculty of Veterinary Medicine, Kasetsart University, \\ Bangkok 10900, Thailand; 2. Department of Companion Animal Clinical Sciences, Faculty of Veterinary Medicine, \\ Kasetsart University, Kamphaeng Saen Campus, Nakhon Pathom 73140, Thailand; 3. Department of Biochemistry, \\ Faculty of Science, Kasetsart University, Bangkok 10900, Thailand; 4. Department of Veterinary Microbiology and \\ Immunology, Faculty of Veterinary Medicine, Kasetsart University, Bangkok 10900, Thailand. \\ Corresponding author: Jatuporn Rattanasrisomporn, e-mail: fvetjpn@ku.ac.th \\ Co-authors: CH: laoperm1137@gmail.com, KC: fsciktc@ku.ac.th, CP: fvetctm@ku.ac.th \\ Received: 03-04-2021, Accepted: 21-06-2021, Published online: 30-07-2021
}

doi: www.doi.org/10.14202/vetworld.2021.1977-1987 How to cite this article: Hlaoperm C, Choowongkomon K, Pruksakorn C, Rattanasrisomporn J (2021) Development of an easy-to-use urease kit for detecting Helicobacter pylori in canine gastric mucosa, Veterinary World, 14(7): 1977-1987.

\begin{abstract}
Background and Aim: Helicobacter pylori is an important pathogen in humans and animals involved in chronic gastritis, leading to the development of gastric cancer. Urease produced by H. pylori is an enzyme that promotes bacterial colonization and can be used clinically as a biomarker of $H$. pylori infection as part of a rapid urease test (RUT). A test with high specificity (95-100\%) would be more convenient and faster than histopathology, bacterial culture, and polymerase chain reaction (PCR). The aim of this study was to develop a simple, cheap, and fast kit for detecting H. pylori infection in the gastric mucosa of canines, which can be used in clinical practice for diagnosing infection with this bacterium.

Materials and Methods: The RUT assays developed were prepared using 1\% agar, 1\% sodium phosphate monobasic, and $1 \%$ urea followed by the addition of 3\% methyl red indicator. The cutoff value of sensitivity of the RUT assay was established using the urease of $H$. pylori ATCC 43504 and color change was monitored for 24 h. Comparisons of the

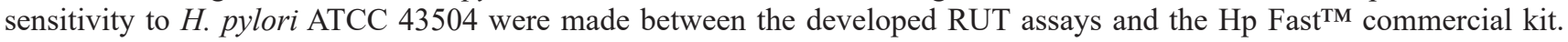
Then, the limit of detection for H. pylori ATCC 43504 number was analyzed by the SYBR Green real-time PCR assay to measure the copy number of the ureC gene. Gastric biopsy samples from the antrum, body, and fundus of the stomach were collected from eight canines presenting with vomiting and gastroenteritis. Analyses were performed on fresh samples using the developed RUT assays and the Hp Fast ${ }^{\mathrm{TM}}$ commercial kit, which were read within 24 h; then, the results were confirmed with SYBR Green real-time PCR. The specificity of the RUT assays was tested with a number of different bacteria, including Staphylococcus pseudintermedius, Proteus spp., Pseudomonas aeruginosa, Klebsiella pneumoniae, Enterococcus spp., Escherichia coli, and Salmonella spp.; H. pylori ATCC 43504 was used as a positive control.
\end{abstract}

Results: The results showed that the developed assays were sensitive to the urease enzyme at $0.1 \mathrm{mg} / \mathrm{mL}$. The lowest detection limit of this assay for H. pylori ATCC 43504 was found to be $10^{2}$ copies at $30 \mathrm{~min}$. The sensitivity of detection of H. pylori in gastric biopsies of canines occurred in a minimum of $30 \mathrm{~min}$. The RUT showed similar results to the Hp Fast ${ }^{\mathrm{TM}}$ commercial kit. In the developed RUT, the color change of the test from red to yellow could be clearly distinguished between the color of the positive test and the negative one; however, in the commercial Hp Fast ${ }^{\mathrm{TM}}$, it was difficult to observe the gel color changein the negative $\mathrm{pH}$ range of 5.8 and the positive $\mathrm{pH}$ of 6.5. The developed RUT was specific for $H$. pylori and did not detect any of the other tested bacteria. The test kit can also be stored for 6 months at $4^{\circ} \mathrm{C}$.

Conclusion: The sensitivity of the developed assays allowed the detection of urease enzyme at a minimum concentration of $0.1 \mathrm{mg} / \mathrm{mL}$. Our RUT could also detect H. pylori from one in eight canine specimens at a minimum of $10^{2}$ copies within $30 \mathrm{~min}$. This RUT is specific to $H$. pylori as it did not detect any of the other tested bacteria.

Keywords: dog, Helicobacter pylori, rapid urease test.

\section{Introduction}

Helicobacter spp. is a spiral-shaped, Gramnegative pathogenic bacterium. Its primary habitat is the gastric mucosa of not only humans but also animals [1]. Helicobacter species have been reported in both wild and domestic mammals having various

Copyright: Hlaoperm, et al. Open Access. This article is distributed under the terms of the Creative Commons Attribution 4.0 International License (http://creativecommons.org/licenses/ by/4.0/), which permits unrestricted use, distribution, and reproduction in any medium, provided you give appropriate credit to the original author(s) and the source, provide a link to the Creative Commons license, and indicate if changes were made. The Creative Commons Public Domain Dedication waiver (http:// creativecommons.org/publicdomain/zero/1.0/) applies to the data made available in this article, unless otherwise stated. dietary habits, such as dogs, cats, mice, swine, cattle, and sheep [2]. The various species of Helicobacter and different strains within the same species may not necessarily cause similar changes in gastric regions. Helicobacter pylori causes changes in the mucosa of the human stomach because of its mobility and its ability to resist high acidity [3]. H. pylori has been identified as a serious cause of peptic ulcerative diseases (gastric and duodenal ulcers), gastritis, chronic and gastric cancer, and even gastric lymphoma [4]. In 2005, Barry Marshall and Robin Warren were awarded the Nobel Prize in Physiology for their work on H. pylori. According to the Nobel Committee, this prize was given for their discovery of the role 
played by $H$. pylori in gastritis and peptic ulcer[5]. This is extraordinary on the grounds that $H$. pylori is the only bacterium known to cause gastric cancer [6]. Therefore, this bacterium has become the target of a large number of studies on the human stomach.

In 1994, the World Health Organization and the International Agency for Research on Cancer designated $H$. pylori as a Class 1 cancer-causing agent and a definite cause of gastric adenocarcinoma in humans [7]. H. pylori is estimated to affect $50 \%$ of the global population, having a presence in both developed and developing nations; its prevalence can be higher than $70 \%$ in developing nations [8]. In Thailand, the incidence of $H$. pylori infection in humans was reported to be $57 \%$ [9]. H. pylori disease occurs essentially within families; it has been asserted that individual-to-individual spread is the most probable method of transmission. Fecal-oral, oral-oral, and gastro-oral transmission routes are likely, especially since $H$. pylori can be discharged through defecation, spit, and vomitus. Given the role of $H$. pylori contamination in gastrointestinal infection, an exact diagnosis of $H$. pylori disease is a necessary foundation for treating different gastrointestinal indications and forestalling genuine complications [10].

Against this background, the diagnostic method for detecting infection in patients with gastritis is important. Standard culture, which is a method for isolating $H$. pylori from stomach biopsies of patients, may take up to 5 to 7 days to achieve optimal growth, and the cultivation of $H$. pylori is labor-intensive and expensive [11]. Then, the growth of $H$. pylori is confirmed according to biochemical tests (positive for oxidase, catalase, and urease) [12]. To date, several more effective assays of $H$. pylori have been developed. Specifically, there are two groups of diagnostic tests for $H$. pylori, namely, invasive tests based on endoscopy in patients, for example, the rapid urease test (RUT), bacterial culture, and histopathology, and non-invasive tests, such as the urease breath test, serology, and the stool antigen test, which are specific and sensitive for $H$. pylori but quite expensive $[10,13]$.

$H$. pylori produces urease, an enzyme that promotes bacterial colonization, and is used clinically as a biomarker for $H$. pylori infection as part of the rapid RUT, having specificity of $95-100 \%$ for infectious agents, depending on the severity of infection. This method is more convenient and faster than histopathology, bacterial culture, and polymerase chain reaction (PCR) $[5,10]$. In addition to H. pylori, other Helicobacter species may infect humans and be associated with gastritis in animals such as canines and have been identified as non-H. pylori Helicobacter [14]. Infection with Helicobacter spp. was reported at a high prevalence in the gastric mucosa of canines; Helicobacter spp. DNA was detectable in the oral cavity of over $70 \%$ of canines. These findings support the possibility of oral-oral transmission between canine oral cavities, which may act as a source of non-H. pylori
Helicobacter spp. infection in humans [14]. Against this background, we were interested in developing a test kit for $H$. pylori in canines with the RUT because it is more convenient and rapid than the other methods mentioned above.

The aim of this study was thus to develop accurate RUT assays to diagnose $H$. pylori infection in the gastric mucosa of canines using a $\mathrm{pH}$-sensitive indicator. If present, $H$. pylori urease metabolizes urea, leading to increased $\mathrm{pH}$, as a result, the test kit developed was positive. The developed RUT assays are cheaper than commercial kits, can be used in clinical practice to detect $H$. pylori in canine gastric mucosa, and can be applied in the clinical diagnosis of $H$. pylori in human gastric mucosa.

\section{Materials and Methods}

\section{Ethical approval}

The animal use protocol was reviewed and approved by the Kasetsart University Animal Use Committee for the Use of Animals in Research and Education, under the protocol number ACKU62-VET-062.

\section{Study period and location}

The study was conducted from February 2019 to November 2020 at the Faculty of Veterinary Medicine, Veterinary Teaching Hospital and Faculty of Science, Kasetsart University.

\section{Animals and samples collection}

Eight canines (four males and four females) which underwent gastroscopy were used in this study. The gastric biopsy samples from the antrum, body, and fundus parts of the stomach, were collected from canines presenting with vomiting and gastroenteritis. The evaluation of the gastric mucosa was based on the procedures of the World Small Animal Veterinary Association and the previous studies of Sousa et al. [15]. Animals' history information was gathered including age, sex, breed, as well as the results of diagnostic records and final diagnosis. Three specimens were taken from each dog as samples to test with the developed RUT assays.

\section{Preparation of the developed RUT assays}

The developed RUT assays were prepared using 1\% agar (Thermo Scientific ${ }^{\mathrm{TM}}$, USA), 1\% sodium phosphate monobasic (Sigma-Aldrich, USA), and 1\% urea (KemAus, Australia). These components were dissolved in distilled water, boiled to completely dissolve the materials, and autoclaved at $121^{\circ} \mathrm{C}$ and 15 psi for $15 \mathrm{~min}$. The agar was cooled to $50-55^{\circ} \mathrm{C}$ and then 3\% methyl red indicator was added, after which the agar solution was mixed thoroughly. One milliliter was distributed per sterile plastic container (containers for contact lenses). The containers were left on a sterile surface until the agar had solidified. The lids of the containers were then closed and stored in a refrigerator at $4-8^{\circ} \mathrm{C}$ until used to develop the RUT assays. 
Determination of the optimal cutoff value for sensitivity to urease of the developed RUT

The test to determine the lowest urease concentration detectable (producing a color change) in the RUT employed the urease in Canavalia ensiformis (Jack bean) powder (Sigma-Aldrich). The urease was diluted in distilled water at concentrations of $0.1,0.01,0.001,0.0001,0.00001$, and $0.000001 \mathrm{mg} /$ $\mathrm{mL}$; approximately $60 \mu \mathrm{L}$ of each concentration was used in the developed RUT assays. These assays were observed for a color change at 1, 3, 5, 10, 20, and $30 \mathrm{~min}$ and $1,2,3,4,5,6$, and $24 \mathrm{~h}$. The negative control was $60 \mu \mathrm{L}$ of Deionized (DI) water, which substituted for the urease.

\section{Bacterial strains and culture conditions}

Reference strains including $H$. pylori ATCC 43504 were used to validate the developed RUT assays. H. pylori ATCC 43504 was cultured on tryptic soy agar (Difco; BBL, USA) with 5\% defibrinated sheep blood (Thermo Scientific ${ }^{\mathrm{TM}}$, Thailand). Agar slants were incubated at $37^{\circ} \mathrm{C}$ for 3 days under a microaerobic atmosphere using a gas pack system (Thermo Scientific ${ }^{\mathrm{TM}}$, Thailand). Other microorganisms used for the specificity test included Staphylococcus pseudintermedius, Proteus spp., Pseudomonas aeruginosa, Klebsiella pneumoniae, Enterococcus spp., Escherichia coli, and Salmonella spp., which were cultured in brain-heart infusion broth (Difco, USA) at $37^{\circ} \mathrm{C}$ for $24 \mathrm{~h}$.

\section{Optimal cutoff value for sensitivity of a RUT}

The test determined the lowest $H$. pylori number that would make the developed RUT assays change color, using $H$. pylori ATCC 43504 in trypticase soy broth (Difco; BBL, USA) medium passed through tenfold serial dilution in phosphate-buffered saline (PBS) buffer. Approximately $60 \mu \mathrm{L}$ of the solution was dispensed into each of the developed RUT assays and the Hp Fast ${ }^{\mathrm{TM}}$ commercial kit. The lids of the containers were closed, samples were incubated at room temperature $\left(25^{\circ} \mathrm{C}\right)$, and color change was observed at 1,3 , $5,10,20$, and $30 \mathrm{~min}$ and every hour up to $24 \mathrm{~h}$. The results were compared between the developed RUT assays and the Hp Fast ${ }^{\mathrm{TM}}$ commercial kit. The negative control was $H$. pylori ATCC 43504 diluted 10 times in $1 \mathrm{X}$ PBS buffer and heated at $100^{\circ} \mathrm{C}$ for $30 \mathrm{~min}$. The genomic DNA of $H$. pylori ATCC 43504 in solution was extracted with the GF-1 Bacterial DNA Extraction Kit (Vivantis, Malaysia), in accordance with the manufacturer's instructions. The limit of detection was analyzed by the SYBR Green real-time PCR assay to measure the copy number of the ureC gene to detect $H$. pylori.

Next, $3.0 \mathrm{~mm}$ biopsy samples of fresh gastric mucosa samples from the stomach antrum, body, and fundus of each canine were collected and individually tested in the developed RUT assays and by the Hp Fast $^{\mathrm{TM}}$ commercial kit. Samples in the developed RUT assay that changed color from red to yellow were considered positive for $H$. pylori. The reading of results was performed at 1, 3, 5, 10, 20, and $30 \mathrm{~min}$ and 1, 2, 3,
$4,5,6$, up to $24 \mathrm{~h}$, and the timing of color changes was analyzed for a possible association with the amount of bacteria in the sample. Genomic DNA from stool specimens of the canines was extracted using the E.Z.N.A. ${ }^{\circledR}$ Tissue DNA Kit (Omega BIO-TEK, USA), in accordance with the manufacturer's instructions. Genomic DNA was detected by SYBR Green real-time PCR in all samples to confirm the results and then considered together with the histopathological diagnosis.

\section{DNA template preparation for standard curve}

H. pylori ATCC 43504 was analyzed with the

GF-1 Plasmid DNA Extraction Kit (Vivantis, Malaysia), in accordance with the manufacturer's instructions. PCR amplification of the ure C gene of $H$. pylori ATCC 43504 was performed using the specific forward primer 5'-TTATCGGTAAAGACACCAGAAA-3' and reverse primer 5'-ATCACAGCGCATGTCTTC-3'. In this study, we used primers specific for the ureC gene of $H$. pylori ATCC 43504 [16]. Total DNA of $H$. pylori ATCC 43504 at $100 \mathrm{ng} / \mu \mathrm{L}(1 \mu \mathrm{L})$ was added to a final volume of $10 \mu \mathrm{L}$. The reaction mixture contained $5.75 \mu \mathrm{L}$ of DI water, $10 \times 0.3 \mathrm{mM} \mu \mathrm{L}(1 \mu \mathrm{L})$ PCR buffer, $2.5 \mathrm{mM} \mu \mathrm{L}$ $(1 \mu \mathrm{L}) \mathrm{dNTP}, 0.25 \mu \mathrm{L}$ of Taq DNA Polymerase, $5 \mu \mathrm{M}$ $(0.5 \mu \mathrm{L})$ forward and reverse primers and the reaction mixture. PCR amplification consisted of initial denaturation at $95^{\circ} \mathrm{C}$ for the target DNA for $3 \mathrm{~s}$, following by 30 cycles of denaturation at $95^{\circ} \mathrm{C}$ for $30 \mathrm{~s}$, annealing at $55^{\circ} \mathrm{C}$ for $30 \mathrm{~s}$, and extension at $72^{\circ} \mathrm{C}$ for $15 \mathrm{~s}$. The final extension was performed at $72^{\circ} \mathrm{C}$ for $5 \mathrm{~min}$ to ensure the full extension of the PCR product. To check for amplification contaminants, the assay was run with no template DNA; $1 \mu \mathrm{L}$ of DI water was substituted for the template. A $146 \mathrm{bp}$ product resulted from the reaction.

The PCR product of $146 \mathrm{bp}$ was cloned into p-GEMT-Vector (Promega Corporation, USA) following the manufacturer's instructions and transformed into host strain E. coli BL21 competent cells. Automated DNA sequencing further confirmed that the expected ureC gene fragment had been cloned into the p-GEMT-Vector, in accordance with the website of the NCBI (National Center for Biotechnology Information) using the BLAST ${ }^{\circledR}$ program.

The plasmid DNA from cloning was extracted using the GF-1 Plasmid DNA Extraction Kit (Vivantis, Malaysia) following the manufacturer's instructions. The DNA solution's absorbance was measured at $260 \mathrm{~nm} 3$ times with a NanoDrop ${ }^{\mathrm{TM}}$ Spectrophotometer (Thermo Scientific ${ }^{\mathrm{TM}}$, USA). Next, $100 \mathrm{ng} / \mu \mathrm{L}$ circular plasmid from cloning was analyzed for the copy number of the ureC gene following formula 1 using the DNA Copy Number and Dilution Calculator program (Thermo Scientific ${ }^{\mathrm{TM}}$ ).

DNA copies $($ copies $/ \mu \mathrm{L})=$

[nanogram] x $6.02 \times 10^{23}(\mathrm{copy} / \mathrm{mol})$

$\times$ DNA amount $(\mathrm{g} / \mu \mathrm{L})$

DNA length $(\mathrm{bp}) \times 660(\mathrm{~g} / \mathrm{mol} / \mathrm{bp})$ 
DNA amount $(\mathrm{g} / \mu \mathrm{L})=$ The measured plasmid concentration value

DNA length $(\mathrm{bp})=$ Plasmid length and the connected genes

The measured plasmid copy numbers of the ure $\mathrm{C}$ gene was diluted in a ten-fold series in DI water at concentrations of $10^{1}-10^{7}$ copy numbers for a standard curve.

\section{SYBR Green real-time PCR for calculating the ureC gene copy number in $\boldsymbol{H}$. pylori ATCC 43504}

For the real-time PCR reaction, the Maxima SYBR Green/ROX qPCR Master Mix (Bio-Rad, USA) was used to determine the copy number of the $H$. pylori ureC gene. The genomic DNA was extracted from the H. pylori ATCC 43504 strain using the GF-1 Bacterial DNA Extraction Kit (Vivantis, Malaysia) following the manufacturer's instructions. It was diluted 10 times in concentrated 1X PBS buffer. The lowest concentrations of $H$. pylori ATCC 43504 that resulted in a positive color change in the developed test kit were calculated by SYBR Green real-time PCR compared with plasmid DNA extracted from cloning, which was used as a standard solution at gene copy numbers of $10^{7}, 10^{6}, 10^{5}, 10^{4}$, $10^{3}, 10^{2}$, and $10^{1}$. SYBR Green real-time PCR amplification of the ureC gene of H. pylori ATCC 43504 was performed using the specific forward and reverse primers mentioned above. The reaction mixture contained $7.5 \mu \mathrm{L}$ of DI water, $5 \mu \mathrm{M}(1.5 \mu \mathrm{L})$ forward and reverse primers, and $12.5 \mu \mathrm{L}$ of (2') Maxima SYBR Green/ ROX qPCR Master Mix (Bio-Rad, USA). Two microliters of DNA plasmid and genomic DNA of $H$. pylori ATCC 43504 were added to each concentration to a final volume of $25 \mu \mathrm{L}$ per reaction. The amplification consisted of initial denaturation at $50^{\circ} \mathrm{C}$ for $5 \mathrm{~min}$, followed by 30 cycles of denaturation at $94^{\circ} \mathrm{C}$ for $30 \mathrm{~s}$, annealing at $59^{\circ} \mathrm{C}$ for $30 \mathrm{~s}$, and extension at $72^{\circ} \mathrm{C}$ for 30 $\mathrm{s}$. This was, in turn, followed by melting curve analysis by setting the initial temperature to $65^{\circ} \mathrm{C}$ increasing by $0.5^{\circ} \mathrm{C}$ every $5 \mathrm{~s}$ to ensure the full extension of the PCR product. A $146 \mathrm{bp}$ product resulted from the reaction. The negative controls were $2 \mu \mathrm{L}$ of DI water, which substituted for the template.

\section{Detection specificity of the developed RUT assays}

The microorganisms were diluted with PBS buffer at $150 \times 10^{6}$ bacterial cells $/ \mathrm{mL}$. McFarland Standard 0.5 was used for the test of the specificity of the developed RUT assays. A number of microorganisms can produce urease, including $S$. pseudintermedius, Proteus spp., P. aeruginosa, and K. pneumoniae. In this study, the urease-negative group included Enterococcus spp., E. coli, and Salmonella spp., while H. pylori ATCC 43504 was used as a positive control. Approximately $60 \mu \mathrm{L}$ of the bacterial solutions were dispensed in the developed RUT assays to detect specificity of the developed RUT assays in other bacteria that are not $H$. pylori. The developed RUT assays were observed for color change at 1, 3, 5, 10,20, and $30 \mathrm{~min}$ and at $1,2,3,4,5$, and $6 \mathrm{~h}$, until $24 \mathrm{~h}$.

\section{Stability test of the developed RUT assays}

To test the shelf life of the developed assays, four groups were established. Group 1 was supplemented with the preservative 1\% methyl paraben (Salicylates And Chemicals Private Limited, India) followed by storage at $25^{\circ} \mathrm{C}$. Group 2 was stored at $25^{\circ} \mathrm{C}$ without the preservative. Group 3 was treated with the preservative and stored at $4^{\circ} \mathrm{C}$. Group 4 was stored at $4^{\circ} \mathrm{C}$ without the preservative. All four groups were tested for detection of the urease enzyme at a concentration of $0.1 \mathrm{mg} / \mathrm{mL}$ and volume of $60 \mu \mathrm{L}$, as revealed by color change. The test lasted 6 months.

\section{Results}

\section{Establishment of RUT sensitivity for detection of urease}

Tests to determine the lowest urease concentration that would change the color in the developed assay were performed using urease from $C$. ensiformis powder (Sigma-Aldrich) diluted to concentrations of 0.1, $0.01,0.001,0.0001,0.00001$, and $0.000001 \mathrm{mg} / \mathrm{mL}$. The developed test kit contains methyl red as a color indicator, which changes from red to yellow when the $\mathrm{pH}$ increases. The results showed that, at the enzyme concentration of $0.1 \mathrm{mg} / \mathrm{mL}$, a noticeable color change occurred in the period of 10-30 min and this color remained clear from $2 \mathrm{~h}$ to $24 \mathrm{~h}$. The enzyme concentrations of $0.01,0.001$, and $0.0001 \mathrm{mg} / \mathrm{mL}$ caused a color change on incubation for $24 \mathrm{~h}$. At enzyme concentrations of 0.00001 and $0.000001 \mathrm{mg} / \mathrm{mL}$ and deionized water, no color change occurred (Figure-1 and Table-1).

\section{Sensitivity of the developed RUT for $H$. pylori ATCC 43504}

After $24 \mathrm{~h}$ of testing with serially diluted 10 -fold $H$. pylori, both the developed RUT and the Hp Fast ${ }^{\mathrm{TM}}$ commercial kit detected H. pylori ATCC 43504. The developed test changed color from red to yellow after $30 \mathrm{~min}$. The commercial kit was also positive as indicated by a change from yellow to blue. The negative control was $H$. pylori ATCC 43504 diluted 10 times in $1 \mathrm{X}$ PBS buffer and heated at $100^{\circ} \mathrm{C}$ (Figure-2).

The genomic DNA was extracted from each serially diluted 10-fold $H$. pylori ATCC 43504 and SYBR Green real-time PCR was used to determine the limit

Table-1: Results of the color change test to determine the sensitivity of the developed RUT to detect urease.

\begin{tabular}{|c|c|c|c|c|c|c|}
\hline \multirow{2}{*}{$\begin{array}{l}\text { Urease enzyme } \\
(\mathrm{mg} / \mathrm{mL})\end{array}$} & \multicolumn{6}{|c|}{ Time to change color } \\
\hline & $<10 \mathrm{~min}$ & $1 \mathrm{~h}$ & 1-2 h & 2-4 h & $4-6 h$ & $24 h$ \\
\hline 0.1 & - & + & + & + & + & + \\
\hline 0.01 & - & - & - & - & - & + \\
\hline 0.001 & - & - & - & - & - & + \\
\hline 0.0001 & - & - & - & - & - & + \\
\hline 0.00001 & - & - & - & - & - & - \\
\hline 0.000001 & - & - & - & - & - & - \\
\hline
\end{tabular}

The plus (+) indicates the concentration of urease that caused a color change from red to yellow and the minus sign (-) indicates a negative result. RUT=Rapid urease test 


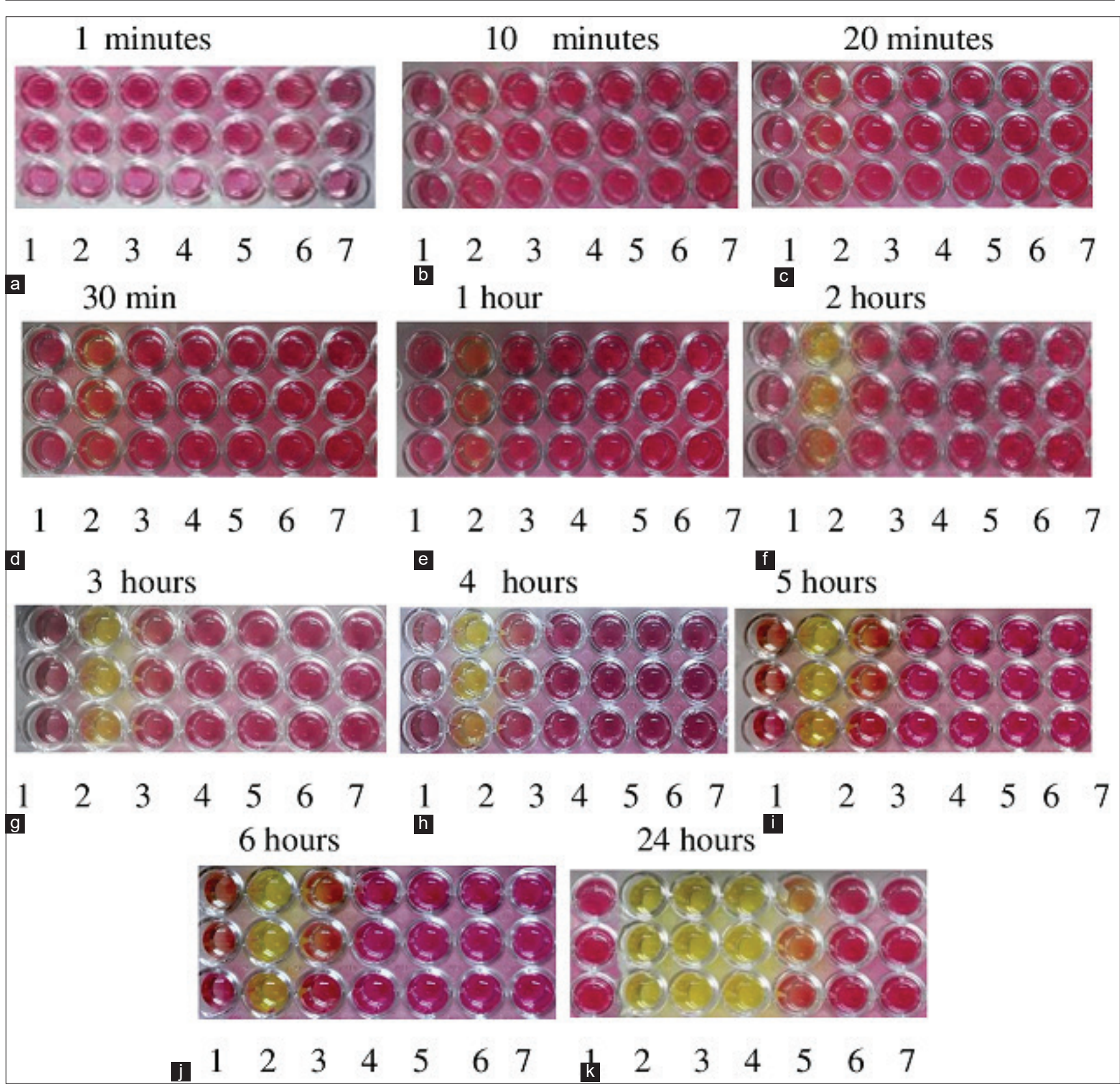

Figure-1: The color change occurring in the developed rapid urease test (RUT) assays to detect urease (assay was repeated 3 times), a, b, c, d, e, f, g, h, i, j, and $k$ changed color from red to yellow at $1 \mathrm{~min}, 10 \mathrm{~min}, 20 \mathrm{~min}, 30 \mathrm{~min}$, and $1 \mathrm{~h}, 2 \mathrm{~h}, 3 \mathrm{~h}, 4 \mathrm{~h}, 5 \mathrm{~h}$ and $6 \mathrm{~h}$, through $24 \mathrm{~h}$, respectively. Well number 1 contained deionized water (Negative control). Well numbers $2,3,4,5,6$ and 7 were urease concentrations $0.1,0.01,0.001,0.0001,0.00001$ and $0.000001 \mathrm{mg} / \mathrm{mL}$, respectively.

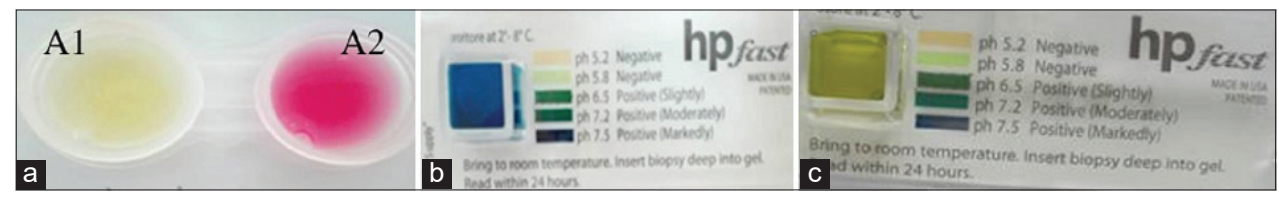

Figure-2: The smallest number of Helicobacter pylori 43504 to cause a color change in the developed rapid urease test (RUT) was compared with commercial kit HP Fast ${ }^{T M}$ incubated at $25^{\circ} \mathrm{C}$ and read within $24 \mathrm{~h}$. (a1) H. pylori ATCC 43504 from a stock culture was tested by the developed RUT. (a2, c) Negative control (b) H. pylori ATCC 43504 from a stock culture tested by the commercial kit HP Fast ${ }^{\mathrm{TM}}$.

of detection of the developed RUT. SYBR Green realtime PCR assay used to measure the ureC gene copy number to detect $H$. pylori ATCC 43504 determined the presence of one copy of the ureC gene per bacterium. The ure $\mathrm{C}$ gene copy numbers for a standard curve were calculated using formula 1 with a range of copy numbers of $10^{7}-10^{1}$; three replicates of each dilution were used. In addition, linear regression analysis showed $\mathrm{R}^{2}=0.999$ and efficiency (E) of $0.97 \%$. Linear regression analysis, plotting the cycle number versus 
the log concentration of the amplicon, gave a straightline plot and a correlation coefficient (Figure-3a). $\mathrm{Gel}$ electrophoresis of the ure $\mathrm{C}$ gene for $10^{7}-10^{1}$ copies indicated that this range still had specific product amplification, and demonstrated that amplification of ure $\mathrm{C}$ occurred at all template concentrations tested (Figure-3b). The result was interpreted as positive based on a $\mathrm{Cq}$ value $\leq 35$. This value tells how many cycles it took to detect a real signal from the samples. From SYBR Green real-time PCR, a reaction curve was established for each sample and thus many $\mathrm{Cq}$ values were obtained.

To determine the analytical sensitivity (detection limit) of the developed RUT, detection values were calculated for $H$. pylori detection number by SYBR Green real-time PCR. This showed that the lowest detected concentration on the dilution of genomic DNA of H. pylori ATCC 43504 was a copy number of $10^{2}$, as shown in Figure-3c. Mean melting temperature $(\mathrm{Tm})$ at $78^{\circ} \mathrm{C}$ indicated specific amplification of H. pylori ATCC 43504 (Figure-3d).

\section{Developed RUT assays with gastroscopic biopsy specimens}

The gastric biopsy samples from eight canines were tested with the developed RUT assays and the Hp Fast ${ }^{\mathrm{TM}}$ commercial kit, which found that one of the canines gave a positive result. It was found that the developed test could detect H. pylori at $30 \mathrm{~min}$ (Figure-4b). The color change was more clearly noticeable over the period from 4 to $24 \mathrm{~h}$, with positive results from the gastric biopsies of the stomach body, antrum, and fundus in both the developed RUT assays and the Hp Fast ${ }^{\mathrm{TM}}$ commercial kit (Figure-4f-h). The Hp Fast ${ }^{\mathrm{TM}}$ commercial kit gave positive results indicated by a color change noticeable at $2 \mathrm{~h}$ and $\mathrm{pH} 6.5$; the color change became clearer over the period from 4 to $24 \mathrm{~h}$. The same results were achieved with the developed RUT assays. H. pylori infection can cause peptic ulcer disease usually localizing in the antrum, leading to increased $\mathrm{pH}$, as a result, the test kits were positive [17]. The Hp Fast ${ }^{\mathrm{TM}}$ commercial kit was used for comparison with the developed RUT.

Table-2 shows the results of the developed RUT assays on biopsies; one of the canines gave a positive

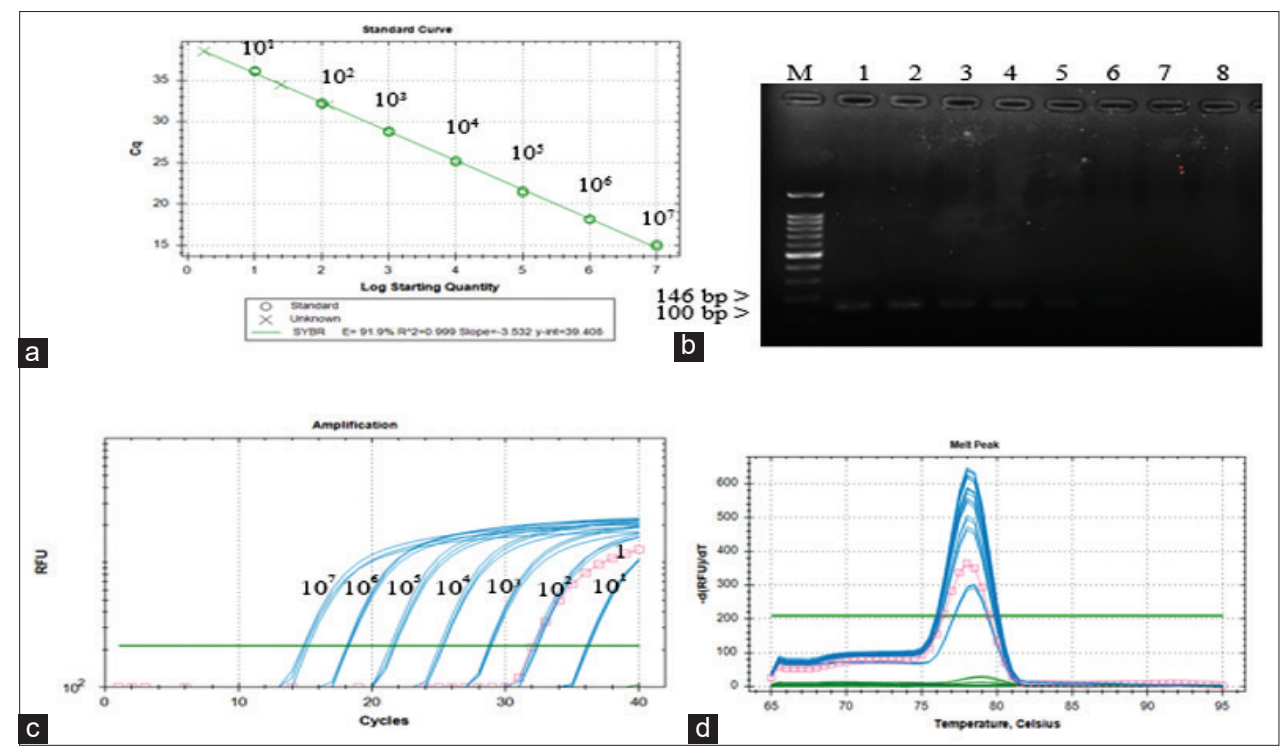

Figure-3: The analytical sensitivity (detection limit) of the developed rapid urease test (RUT). Detection values were calculated by SYBR green real time-PCR. (a) The ureC gene copy numbers for the standard curve were calculated with formula 1 with a range from $10^{1}$ to $10^{7}$ copy numbers (green line). (b) Gel electrophoresis specific to ureC gene 107$10^{1}$ copies; this range still had a specific product of $146 \mathrm{bp}$, lane $\mathrm{M}, 100$-bp markers; lanes $1-7,10^{7}-10^{1}$ copies of the Helicobacter pylori ureC gene, respectively; lane 8, deionized water. (c) The analytical sensitivity of the developed RUT, detection values calculated by SYBR green real time-PCR, detected $10^{2}$ copy numbers (pink line). (d) Mean of $\mathrm{Tm}$ at $78^{\circ} \mathrm{C}$ indicated specific amplification of $H$. pylori ATCC 43504.

Table-2: The results of the developed RUT, Hp Fast ${ }^{T M}$ and SYBR Green real time-PCR assays and histopathological diagnosis based on the biopsy samples from eight canines.

\begin{tabular}{lllll}
\hline Canine & Developed RUT assays & Hp Fast & Real time-PCR & Histopathological diagnosis \\
\hline 1 & $-v e$ & $-v e$ & $-v e$ & Normal gastric mucosa \\
2 & $-v e$ & $-v e$ & $-v e$ & Normal gastric mucosa \\
3 & $+v e$ & $+v e$ & $+v e$ & Chronic enteritis duodenitis \\
4 & $-v e$ & $-v e$ & $-v e$ & Normal gastric mucosa \\
5 & $-v e$ & $-v e$ & $-v e$ & N/A \\
6 & $-v e$ & $-v e$ & $-v e$ & No inflammatory, hyperplasia or neoplasia \\
7 & $-v e$ & $-v e$ & $-v e$ & Ulcerative eosinophilic gastritis \\
8 & $-v e$ & $-v e$ & $-v e$ &
\end{tabular}

+ ve=positive, - ve=negative and N/A=not available, RUT=Rapid urease test 

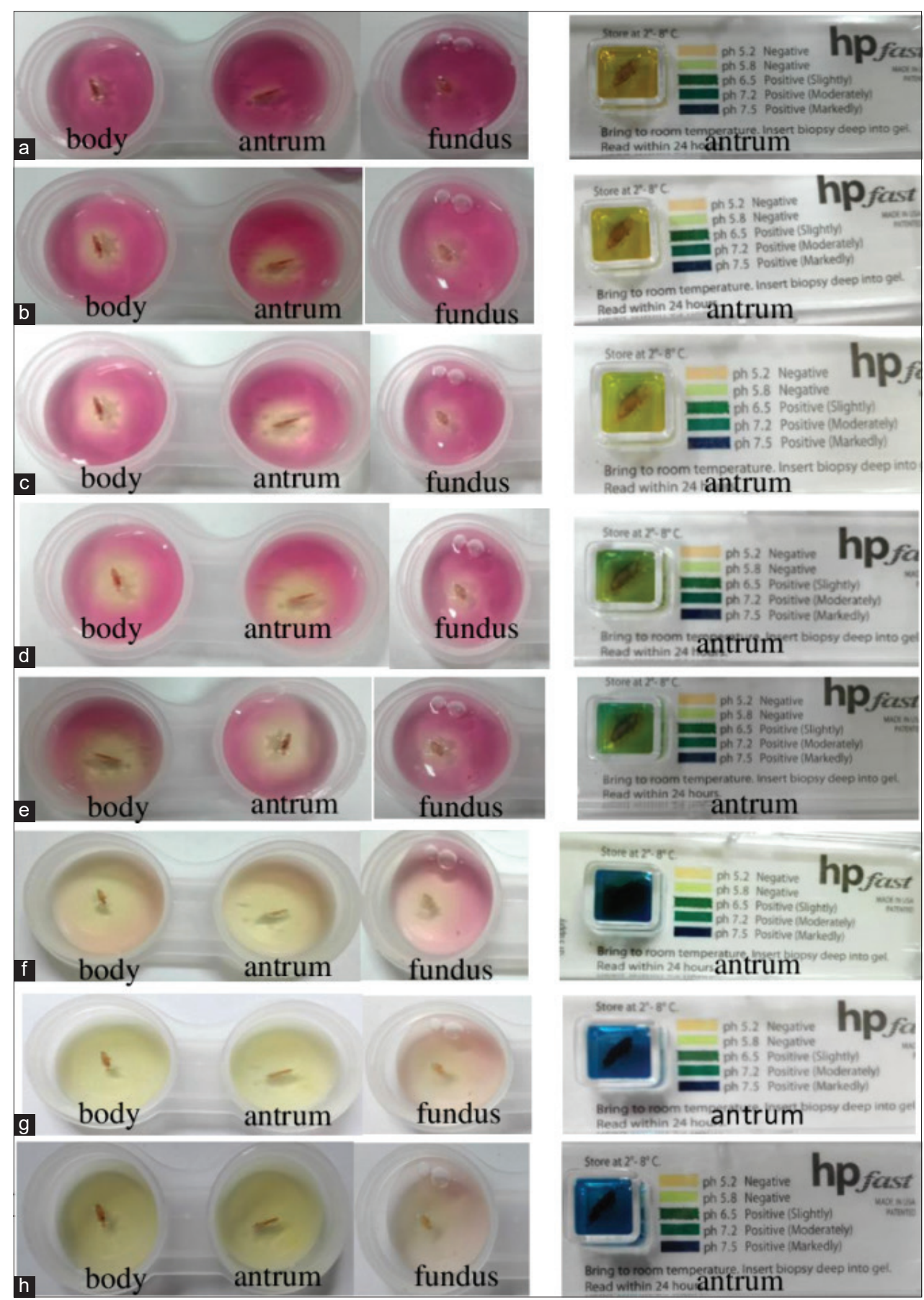

Figure-4: Gastric biopsy samples of the body, antrum and fundus were analyzed by the developed rapid urease test and compared with the HP Fast ${ }^{T M}$ commercial kit. ( $a, b, c, d, e, f, g$, and $h$ ) caused a color change from red to yellow at 3 min, 30 min, and 1 h, 2 h, $3 \mathrm{~h}, 4 \mathrm{~h}$, and overnight, curing up to $24 \mathrm{~h}$, respectively.

result. The results were confirmed by SYBR Green real-time PCR. The ureC gene copy number was used to determine the number of H. pylori in biopsy samples, which were positive at a copy number of $4.78 \times 10^{9}$ and produced a $\mathrm{Cq}$ value of 11.64 . When a dog with a history of chronic vomiting was tested histopathologically, it was found that it had symptoms of chronic enteritis duodenitis $H$. pylori infection alters acids in the duodenum, produces abnormal duodenal movement that cause chronic enteritis, and leads to manifestations of ulcerative colitis $[17,18]$.

\section{The specificity of the developed RUT assays}

Specificity tests of the developed RUT assays used a bacterial concentration of $50 \times 10^{6}$ cells $/ \mathrm{mL}$ (McFarland Standard 0.5) at a volume of $60 \mu \mathrm{L}$ (Table-3). The negative control was 1X PBS buffer. Samples were incubated for $24 \mathrm{~h}$. The results were negative for $S$. pseudintermedius, Proteus spp., $P$. aeruginosa, K. pneumoniae, Enterococcus spp., $E$. coli, and Salmonella spp (Figure-5b-h). H. pylori ATCC 43504 (positive control) was positive, with the developed test color changing from red to yellow after 50 min (Figure-5a). 


\section{Stability test of the developed RUT}

A test of the stability of the developed RUT was conducted at 6 months with urease at a concentration of $0.1 \mathrm{mg} / \mathrm{mL}$ and a volume of $60 \mu \mathrm{L}$. Then, color change was observed and the results were recorded. In Group 1, 1\% methyl paraben (Salicylates And Chemicals Private Limited) was added at $25^{\circ} \mathrm{C}$. Group 2 was tested without the methyl paraben and kept at $25^{\circ} \mathrm{C}$. The results showed that Group 1

Table-3: Results of specificity tests of the developed RUT with a bacterial concentration of $150 \times 10^{6} \mathrm{cell} s / \mathrm{mL}$ (McFarland Standard 0.5).

\section{Bacterial species Color change of the developed test

$\min \quad h$

5102030405012345624

H. pylori ATCC $43504-c_{-}-c_{+}++++++$

S. pseudintermedius $--_{-}--,-----$

Proteus spp. $\quad-\quad----------$

$P$. aeruginosa $\quad-\quad-\quad-------$

K. pneumoniae $\quad-\quad---------$

Enterococcus spp. $\quad-\quad-\quad-\quad-------$

E. coli $\quad-\quad-\quad-------$

Salmonella spp. $\quad-\quad-\quad-\quad-\quad---\ldots$

$+=$ Positive, $-=$ Negative, $H$. pylori=Helicobacter pylori,

S. pseudintermedius =Staphylococcus pseudintermedius,

$P$. aeruginosa $=P$ seudomonas aeruginosa,

K. pneumonia=Klebsiella pneumoniae, $E$. coli=Escherichia coli, RUT=Rapid urease test exhibited a slower color change than Group 2; when kept for 2 weeks, the gels of both groups were dry because the high temperature caused evaporation, and the tests could not be continued (Figure-6a). In Group 3, the developed RUT was supplemented with $1 \%$ methyl paraben and stored at $4^{\circ} \mathrm{C}$. In Group 4 , storage was performed at $4^{\circ} \mathrm{C}$ without methyl paraben. In Group 3, the color change occurred after 3 months in storage, but was slower than in Group 4. In Group 4, urease could be detected for 6 months (Figure-6b).

\section{Discussion}

H. pylori exhibits the unusual characteristic of producing large amounts of urease [19]. Thus, we developed the RUT assays carried out in a small amount of agar containing urea and a $\mathrm{pH}$ indicator. If urease is present, the urea is broken down into ammonia and carbamate, thus raising the $\mathrm{pH}$, and the $\mathrm{pH}$ indicator changes from red to yellow. The reaction usually occurs within $24 \mathrm{~h}$. The developed RUT could detect a minimum of $0.1 \mathrm{mg} / \mathrm{mL}$ urease after $30 \mathrm{~min}$ of incubation, and the change of color from red to yellow was clearly observable within $2 \mathrm{~h}$ (Figure-1d-f).

Next, we investigated the sensitivity (detection limit) of the developed RUT for H. pylori ATCC 43504 and compared the results with those from the commercial kit Hp Fast ${ }^{\mathrm{TM}}$, read within 24 h. The developed
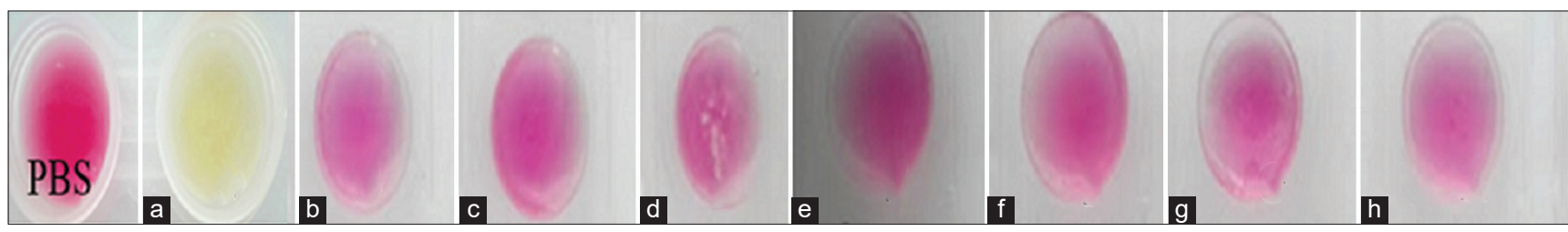

Figure-5: Results of the specificity test of the developed rapid urease test (RUT) with bacterial concentration at $150 \times 10^{6}$ cells $/ \mathrm{mL}$ (McFarland Standard 0.5). Testing was with Helicobacter pylori ATCC 43504 and the results of the RUT assays were positive indicated by the color change from red to yellow (a). Then, b, c, d, e, f, g, h were Staphylococcus pseudintermedius, Proteus spp., Pseudomonas aeruginosa, Klebsiella pneumoniae, Enterococcus spp., Escherichia coli, and Salmonella spp., respectively, and all tested negative.

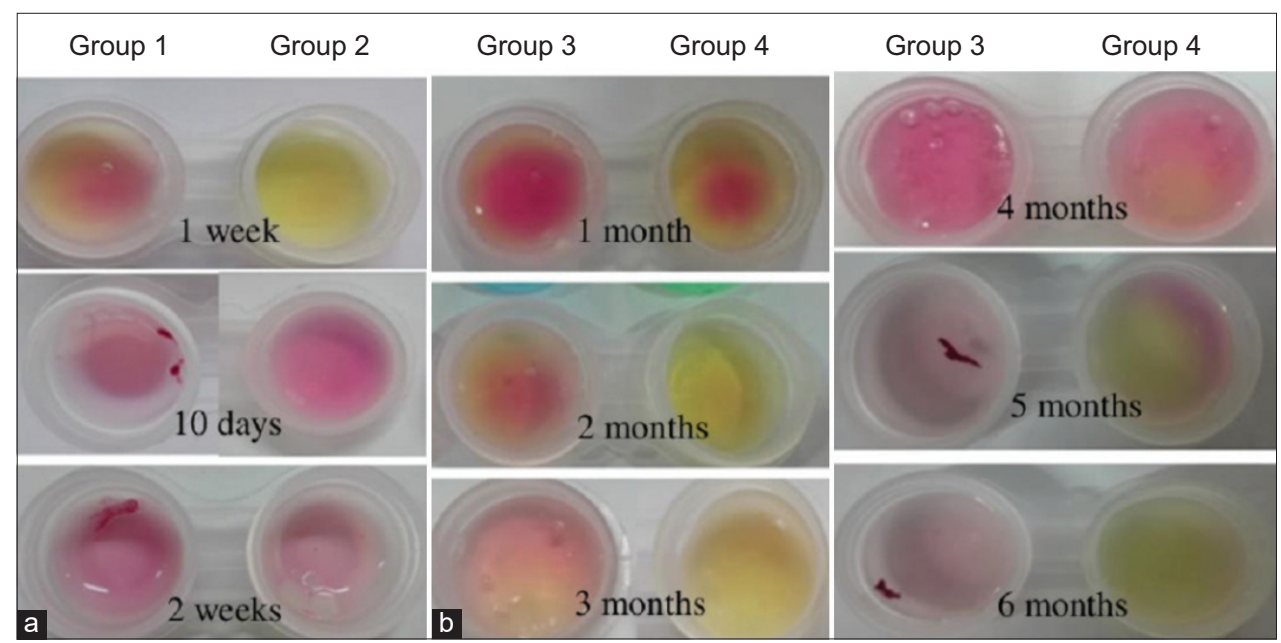

Figure-6: Results of stability test of the developed rapid urease test at 6 months. (a) Gels were stored at $25^{\circ} \mathrm{C}$ for 2 weeks; both groups of gels were dry. (b) Gels were stored at $4^{\circ} \mathrm{C}$, Group 4 was able to detect urease for up to 6 months. 
test produced a color change from red to yellow at $30 \mathrm{~min}$ up to $24 \mathrm{~h}$, and this correlated with the positivity in the commercial kit Hp Fast ${ }^{\mathrm{TM}}$, in which the color changed from yellow to blue (Figure-2). The lowest concentration of $H$. pylori ATCC 43504 was selected to calculate the ureC copy number by SYBR Green real-time PCR, in view of the fact that there is just one copy of ureC per bacterium, so it is suitable for calculating the load of $H$. pylori [20]. The quantitative real-time PCR assay for ureC gene was used to calculate the $H$. pylori number to determine the limit of detection of the developed RUT. The PCR product obtained from the real-time PCR reaction of each bacterial species has an appropriate melting temperature (Tm) that was displayed with DNA peak in the graph, which determines the conditions under which these will bind to target gene [21]. The results of the melting point curve show that there was no mispriming in the test; the use of $\mathrm{Tm}$ at $78^{\circ} \mathrm{C}$ ensures that the primer used only amplifies the ure $\mathrm{C}$ target gene, as indicated by the formation of a single peak (Figure-3d). The mean $\mathrm{Cq}$ was calculated for each bacterial concentration, the $\mathrm{Cq}$ values $\leq 35$ were considered as positive results. The presence of a DNA band specific for the ureC gene by gel electrophoresis was indicated by a product size of $146 \mathrm{bp}$ (Figure-3b). In this study, we used primers specific to the ureC gene of $H$. pylori ATCC 43504 , as in a previous study [16]. The results of analysis of the nucleotide sequence database through the NCBI website found that the primers were specific to the ureC gene of $H$. pylori ATCC 43504 at $99.29 \%$.

SYBR Green real-time PCR analyses revealed that the developed RUT can detect infection at a copy number of $10^{2}$; the $\mathrm{Cq}$ value was 32 and the $\mathrm{Tm} 78^{\circ} \mathrm{C}$ (Figure-3c). A copy number lower than $10^{2}$ will give a negative result, based on one copy of the ure $\mathrm{C}$ gene per bacterium [20]. This result is in accordance with a previous study [22], in which the results of a RUT for concentrated urease production of Helicobacter species were found to be positive at $10^{2}$ copies. In the developed RUT, the color change of the test from red to yellow could clearly distinguish positivity and negativity, but in the commercial kit, Hp Fast ${ }^{\mathrm{TM}}$, it is difficult to observe the gel color change upon a negative result at $\mathrm{pH} 5.8$ and a positive result at $\mathrm{pH}$ 6.5. Therefore, the RUT results should be analyzed together with the performance of SYBR Green real-time PCR to confirm either a positive or a negative result.

The developed RUT was used to test gastric biopsy samples from eight canines, reading the results within $24 \mathrm{~h}$, and compared with the commercial kit Hp Fast $^{\mathrm{TM}}$. Of the eight canines assayed, one case tested positive by the developed RUT, commercial kit Hp Fast $^{\mathrm{TM}}$ (GI supply, USA), and SYBR Green real-time PCR, while the remaining seven cases were negative. At $30 \mathrm{~min}$, the developed test detected the target bacterium in the body, fundus, and antrum of the stomach based on the color change. This study was consistent with the previous studies by Sousa et al. [15] that used a RUT to detect $H$. pylori in the stomach antrum, body, and fundus of 32 cats from gastric biopsies. The detection of the RUT in cats can also be detected at $30 \mathrm{~min}$. In this study, the histopathological diagnosis in the positive case correlated with symptoms of chronic enteritis duodenitis while the other seven canines gave negative results but had symptoms of ulcerative eosinophilic gastritis (Table-2). When confirmed by SYBR Green real-time PCR, it was found that $H$. pylori tested negative at $9.3 \times 10^{1}$ copies and a $\mathrm{Cq}$ value at 39.58 . It was previously reported by Bermejo et al. [23], with human patients with gastroenteritis, that positive RUT results required $H$. pylori infection at a minimum of $10,000 \mathrm{CFU} / \mathrm{mL}$. Positive results in RUT assays are strongly dependent on the number of $H$. pylori in a specimen.

The specificity of the developed RUT assays was tested using a bacterial concentration of $150 \times 10^{6}$ cells $/ \mathrm{mL}$ (McFarland Standard 0.5); the results showed positivity for $H$. pylori ATCC 43504 (Figure-5a). The time at which the test turns positive depends on the concentration of bacteria and the urease $[22,24]$. The urease-positive bacteria used in prior RUT-specificity research included $S$. pseudintermedius, Proteus spp., P. aeruginosa, and K. pneumoniae [25]. At the same time, groups of bacteria capable of producing urease were negative (Figure-5b-e). The previous reports showed that the developed RUT could detect a minimum of $0.1 \mathrm{mg} / \mathrm{mL}$ urease, so negative results may be due to the urease not being sufficiently released or because the concentration was $<0.1 \mathrm{mg} / \mathrm{mL}$. The urease-negative group included Enterococcus spp., E. coli, and Salmonella spp. (Figure-5f-h). Therefore, the developed RUT did not detect any other infection. However, it is specific to members of the genus Helicobacter that can produce urease and release the enzyme at a concentration $>0.1 \mathrm{mg} / \mathrm{mL}$.

The developed test kit can be stored at $4^{\circ} \mathrm{C}$ for 6 months with the lid tightly closed (Figure-6b). However, when stored at $25^{\circ} \mathrm{C}$, the developed RUT dried out after 2 weeks and could not be used. Since the test kit has a gel-like state, it can evaporate and dry at elevated temperatures (Figure-6a). This study showed that methyl paraben interfered with the function of the developed RUT (Figure-6).

The developed RUT should be read within $24 \mathrm{~h}$ with a closed lid to avoid false-positive results from contamination by bacteria that are not $H$. pylori, such as Proteus, Yersinia, Klebsiella, and Pseudomonas, which can produce urease; urea is hydrolyzed to produce ammonia, leading to an increase in $\mathrm{pH}$ causing a positive test result [26]. In this study, flaws were found in the substance used as it was not only opaque white plastic, but also too thick, making it difficult to observe any color change. The observed color change was less clear than with the Hp Fast ${ }^{\mathrm{TM}}$ commercial kit. Furthermore, observation of the experiments required repeated opening and closing of lids, which was inconvenient and created a risk of microbial contamination. 
Therefore, it is recommended that clear and translucent plastic be used for convenience and to minimize contamination. We will continue to develop the test and find suitable materials.

\section{Conclusion}

The developed RUT approach used the RUT technique to detect urease produced by $H$. pylori. The developed assay was sensitive to urease at a concentration of $0.1 \mathrm{mg} / \mathrm{mL}$ at $30 \mathrm{~min}$. The results were analyzed with SYBR Green real-time PCR. The developed RUT could detect $H$. pylori ATCC 43504 at a minimum of $10^{2}$ copies. The developed RUT should be read within $24 \mathrm{~h}$, not only with closed lids but also upon storage at $4^{\circ} \mathrm{C}$ to avoid contamination from bacteria in the environment.

\section{Authors' Contributions}

JR: Principle investigator, designed the study, drafted, critically revised the manuscript, and collected samples. $\mathrm{CH}$ : Designed and managed this research, did laboratory works, and wrote the manuscript. KC: Participated in the design of the study and interpretation of the data. CP: Participated in the bacterial strains and culture conditions. All authors read and approved the final manuscript.

\section{Acknowledgments}

The authors would like to acknowledge the financial support from the Faculty of Veterinary Medicine, Kasetsart University and Kasetsart University Research and Development Institute, Thailand, (Grant no. FF(KU)25.64). They would also like to thank the staff of the endoscopic clinic of Veterinary Teaching Hospital, Kasetsart University for their kind help with specimen collection and medical record data support.

\section{Competing Interests} interests.

The authors declare that they have no competing

\section{Publisher's Note}

Veterinary World remains neutral with regard to jurisdictional claims in published institutional affiliation.

\section{References}

1. Wesley, I.V. (2014) Helicobacter. In: Robinson, R., editor. Encyclopedia Of Food Microbiology. $2^{\text {nd }}$ ed. Academic Press, Cambridge, Massachusetts. p193-199.

2. Youssef, A., Afifi, A., Hamed, A. and Enany, M. (2020) First report of PCR-based detection of Helicobacter species DNA in Camelus dromedarius in Egypt. Vet. World, 13(9): 1898-1901.

3. Miqueleiz-Zapatero, A., Alba-Rubio, C., DomingoGarcía, D., Cantón, R., de la Pedrosa, E.G., Aznar-Cano, E., Leiva, J., Montes. M., Sánchez-Romero, I., RodríguezDíaz, J.C. and Alarcón-Cavero, T. (2020) First national survey on the diagnosis of Helicobacter pylori infection in clinical microbiology laboratories in Spain. Enferm. Infect. Microbiol. Clin. (English Ed)., 38(9): 410-416.

4. Suharsono, H., Muttaqin, Z., Tenaya, I.W., Agustina, K.K. and
Prawiro, S.R. (2019) Antigen of 49.6-kDa sub unit pili protein of Helicobacter pylori as a potential biomarker for early and rapid detection of the infection. Vet. World, 12(6): 769-773.

5. Prashar, A., Lozano-Ruf, A. and Jones, N.L. (2019) Helicobacter pylori infection. In: Kuipers, E.J., editor. Encyclopedia of Gastroenterology. $2^{\text {nd }}$ ed. Academic Press, Cambridge, Massachusetts. p24-32.

6. Ding, L., Sontz, E.A., Saqui-Salces, M. and Merchant, J.L. (2021) Interleukin-1 $\beta$ suppresses gastrin via primary cilia and induces antral hyperplasia. Cell. Mol. Gastroenterol. Hepatol., 11(5): 1251-1266.

7. Barukčić, I. (2018) Helicobacter pylori is the cause of gastric cancer. J. Health Sci. Med. Res., 1(1): 43-50.

8. de Oliveira, I.A. and de Oliveira Corvelo, T.C. (2021) ABH and Lewis blood group systems and their relation to diagnosis and risk of Helicobacter pylori infection. Microb. Pathog., 152: 104653.

9. Deankanob, W., Chomvarin, C., Hahnvajanawong, C., Intapan, P.M., Wongwajana, S., Mairiang, P. and Sangchan, A. (2006) Enzyme-linked immunosorbent assay for serodiagnosis of Helicobacter pylori in dyspeptic patients and volunteer blood donors. Southeast Asian $J$. Trop. Med. Public Health, 37(5): 958-965.

10. Altamimi, E., Alsharkhat, N., AlJawarneh, A., Hamad, M.R., Assi, A.A., Alawneh, S. and Al-Ahmad, M. (2020) Declining prevalence of Helicobacter pylori infection in Jordanian children, report from developing country. Heliyon, 6(7): e04416.

11. Lee, J.W., Kim, N., Nam, R.H., Lee, S.M., Kwon, Y.H., Sohn, S.D. and Jung, H.C. (2019) Favorable outcomes of culture-based Helicobacter pylori eradication therapy in a region with high antimicrobial resistance. Helicobacter, 24(2): e12561.

12. Mayyas, A., Abu-Sini, M., Amr, R., Akasheh, R.T., Zalloum, W., Khdair, A. and Abu-Qatouseh, L. (2021) Novel in vitro and in vivo anti-Helicobacter pylori effects of pomegranate peel ethanol extract. Vet. World, 14(1): 120-128.

13. Lian, D.W., Xu, Y.F., Deng, Q.H., Lin, X.M., Huang, B., Xian, S.X. and Huang, P. (2019) Effect of patchouli alcohol on macrophage mediated Helicobacter pylori digestion based on intracellular urease inhibition. Phytomedicine, 65: 153097.

14. Recordati, C., Gualdi, V., Tosi, S., Facchini, R.V., Pengo, G., Luini, M. and Scanziani, E. (2007) Detection of Helicobacter spp. DNA in the oral cavity of dogs. Vet. Microbiol., 119(2-4): 346-351.

15. Sousa, D.A., Cascon, C.M., Mello, M.F., Leite, J.S., Medeiros, M.A., Fonseca, A.B. and Ferreira, A.M.R. (2017) Helicobacter spp. in domestic cats: Identification and relationship with anatomical and histopathological gastric changes in animals of blood group A. Pesqui. Vet. Bras., 37(12): 1467-1473.

16. He, Q., Wang, J.P., Osato, M. and Lachman, L.B. (2002) Real-time quantitative PCR for detection of Helicobacter pylori. J. Clin. Microbiol., 40(10): 3720-3728.

17. Harpaz, N. and Polydorides, A.D. (2020) Upper gastrointestinal manifestations of inflammatory bowel disease. Surg. Pathol. Clin., 13(3): 413-430.

18. Azadbakht, S., Esmaili, A. and Rahmani, P. (2020) Comparison of clinical symptoms after Helicobacter pylori eradication in functional dyspepsia patients based on endoscopic view of antral gastropathy. New Microbes New Infect., 38: 100806.

19. Barazorda-Ccahuana, H.L., Gómez, B., Mas, F. and Madurga, S. (2020) Effect of $\mathrm{pH}$ on the supramolecular structure of Helicobacter pylori urease by molecular dynamics simulations. Polymers, 12(11): 2713.

20. Shukla, S.K., Prasad, K.N., Tripathi, A., Ghoshal, U.C., Krishnani, N. and Nuzhat, H. (2011) Quantitation of Helicobacter pylori ure $\mathrm{C}$ gene and its comparison with different diagnostic techniques and gastric histopathology. $J$. Microbiol. Methods, 86(2): 231-237. 
21. Nurjayadi, M., Pertiwi, Y.P., Islami, N., Azizah, N., Efrianti, U.R., Saamia, V. and El-Enshasye, H.A. (2019) Detection of the Salmonella Typhi bacteria in contaminated egg using real-time PCR to develop rapid detection of food poisoning bacteria. Biocatal Agric. Biotechnol., 20(1): 101214.

22. Michetti, P., Corthésy-Theulaz, I., Davin, C., Haas, R., Vaney, A.C., Heitz, M. and Blum, A. (1994) Immunization of BALB/c mice against Helicobacter felis infection with Helicobacter pylori urease. Gastroenterology, 107(4): 1002-1011.

23. Bermejo, N.F., Boixeda, D., Gisbert, J.P., Defarges, V., Sanz, J.M., Redondo, C. and de Argila, C.M. (2002) Rapid urease test utility for Helicobacter pylori infection diagnosis in gastric ulcer disease. Hepatogastroenterology, 49(44): 572-575.

24. Uotani, T. and Graham, D.Y. (2015) Diagnosis of Helicobacter pylori using the rapid urease test. Ann. Transl. Med., 3(1): 1-17.

25. Dheyab, A.S., Aljumaili, O.I. and Hussein, N.M. (2018) Study of virulence factors in urease-positive bacteria isolated from urinary tract infections clinical specimens. $J$. Pure Appl. Microbiol., 12(3): 1465-1472.

26. Nevoa, J.C., Rodrigues, R.L., Menezes, G.L., Lopes, A.R., Nascimento, H.F., Santiago, S.B. and Barbosa, M.S. (2017) Molecular technique for detection and identification of Helicobacter pylori in clinical specimens: A comparison with the classical diagnostic method. J. Bras. Pathol. Med. Lab., 53(1): 13-19.

$* * * * * * * *$ 